\title{
Covid -19 Sürecinde Altın ve Petrol Fiyatlarının Bitcoin Üzerindeki Asimetrik Etkisi Filiz YILDIZ CONTUK*
}

Geliş Tarihi (Received): 20.05.2021 - Kabul Tarihi (Accepted): 27.09.2021

\section{$\ddot{\mathbf{O} z}$}

COVID-19'un başlangıcı, 2020'nin belirleyici olayı haline geldi ve kripto para birimleri de dahil olmak üzere tüm dünyadaki finansal piyasaları etkiledi. Bu süreçte, altın ve diğer emtialar gibi güvenli bir liman olarak görülmeye başlanan kripto para birimlerine ve diğer dijital varlıklara yatırıma olan ilgi arttı. $\mathrm{Bu}$ amaçla çalışmada Covid-19 sürecinde, altın ve petrol fiyatlarında meydana gelen şokların Bitcoin fiyatları üzerindeki asimetrik etkisi incelenmiştir. Çalışmada Doğrusal Olmayan Gecikmesi Dağıtılmış Otoregresif (NARDL) analiz yöntemi kullanılmıştır. Analizin sonucunda, uzun vadede altın fiyatlarında meydana gelen negatif şokların Bitcoin fiyatlarını olumlu etkilediği, petrol fiyatlarında meydana gelen negatif şokların ise Bitcoin fiyatlarını olumsuz etkilediği sonucuna ulaşılmıştır. Uzun vadede altın ve petrol fiyatlarında meydana gelen pozitif şokların ise Bitcoin fiyatları üzerinde istatistiki olarak anlamlı bir etkisinin olmadığı görülmüştür. Kısa vadede ise hem altın hem de petrol fiyatlarında meydana gelen pozitif şokların Bitcoin fiyatlarını olumlu etkilediği, negatif şokların ise olumsuz etkilediği tespit edilmiştir. Sonuç olarak, Bitcoin'in küresel yatırımcılar için finansal çeşitlendirmede ideal olabileceği ve yeni bir sanal altın olarak piyasalardaki yerini alabileceği görülmüştür.

Anahtar Kelimeler: Bitcoin, Altın, Brent Petrol, Covid-19, NARDL

\section{Asymmetric Effects of Gold and Oil Prices on Bitcoin in the Covid -19 Process}

\begin{abstract}
The onset of COVID-19 has become the defining event of 2020 and has affected financial markets all over the world, including cryptocurrencies. In this process, the interest in investing in cryptocurrencies and other digital assets, which started to be seen as a safe haven like gold and other commodities, increased. For this purpose, in this study, the asymmetric effect of shocks in gold and oil prices on Bitcoin prices during the Covid-19 process was examined. Nonlinear Autoregressive Distributed Lag (NARDL) analysis method was used in the study. As the end of the analysis, it was concluded that negative shocks in gold prices in the long term affect Bitcoin prices positively, while negative shocks in oil prices affect Bitcoin prices negatively. It has been observed that positive shocks in gold and oil prices in the long term do not have a statistically significant effect on Bitcoin prices. In the short term, it has been determined that positive shocks in both gold and oil prices affect Bitcoin prices positively, while negative shocks have a negative impact on it. In conclusion, it is observed that Bitcoin can be ideal for financial diversification for global investors and take its place in the markets as a new virtual gold.
\end{abstract}

Keywords: Bitcoin, Gold, Brent Oil, Covid-19, NARDL

\footnotetext{
* Dr., Muğla Sıtkı Koçman Üniversitesi, Fethiye A.S.M.K. Meslek Yüksekokulu, Muhasebe ve Vergi Bölümü, fcontuk@mu.edu.tr
} 


\section{Giriş}

Yirmi birinci yüzyılın başındaki mali krizler, özellikle 2008 mortgage krizi, dış şoklara karşı yüksek kırılganlık gösteren mevcut para sistemine olan güveni sarsmıştır. Mortgage piyasası krizi ile başlayan, küresel boyuttaki ekonomik ve finansal kriz esnasında altın fiyatı yoğun bir artış gösterirken diğer varlıklarda kayıplar yaşanmıştır. Yine bu dönemde, yeni dijital dünya ekonomisinin başlangıcını işaret eden kripto para birimleri ortaya çıkmıştır (Al-Naif, 2020:1). Kripto para birimleri, hükümetler tarafından değil, katılımcıların o para birimine atanan değere olan güveni ve inancı tarafından desteklendiğinden, itibari para birimlerini tamamlayacak ve bazı durumlarda ikame edecek şekilde tasarlanmıştır (Corelli, 2018:1). Kripto para piyasasındaki tüm kripto paraların atası ve en çok bilineni olan Bitcoin, herhangi bir merkezi otoriteden veya merkez bankasından bağımsız alternatif bir ödeme sistemi olarak 3 Ocak 2009'da uygulamaya konulmuştur. Bununla birlikte, Bitcoinin değer biriminin ticarete uygunluğu göz önüne alındığında, daha sonra bir yatırım varlığı olarak değerlendirilmiştir (Bauri vd., 2018: 224). Bugünün kripto para birimlerinin en büyüğü olan Bitcoin'in bir yatırım varlığı olarak ortaya çıkmasıyla, giderek artan sayıda uluslararası katılımcı bu kripto para piyasasına dahil olmuştur.

COVID-19 salgını ve Rusya-Suudi Arabistan petrol fiyatı savaşı, 2020'nin ilk çeyreğinde küresel ekonomik ve finansal sistemi istikrarsızlaştırdı. Uluslararası borsalar, vadeli işlemler ve ham petrol fiyatları art arda düştü (Ghorbel ve Jeribi, 2021:1). Ayrıca COVID-19 krizi sırasında, kripto para birimleri dalgalanma yaşadı ve en önemli kripto para birimi olan Bitcoin'in Temmuz 2020'deki Twitter hack'i gibi suç eylemleriyle ilişkilendirilmesiyle itibarları zedelendi. Bu pazardaki bir dizi olumsuz olaya rağmen, kripto para birimine yatırım yapmak, yatırımcılar arasında kendi paralarını kazanmak açısından popülerlik kazanmaya başladı. Çünkü, kripto para birimleri gelecek için büyük umutlar vadeden bir araç olarak görülüyor. Çünkü daha fazla verimlilik, daha az bürokrasi ve daha fazla şeffaflık sunarak, geleneksel bankacılık ürünlerinden daha iyi performans gösterme potansiyeline sahiptirler. Bitcoin, taraflar arasında değer transferini kolaylaştıran dijital bir varlıktır. Eşler arası ağ ve kriptografik protokollere dayalı olarak, internet üzerinden ve finansal aracılara ihtiyaç duymadan, kullanıcıların aynı nakit parada olduğu gibi işlemler yapmasına olanak tanımaktadır. (Ji vd., 2018:203-204). Bitcoin emtiaların (yani altın) ve piyasaya hâkim para birimlerinin özelliklerini birleştirir ve bu nedenle sentetik emtia parası olarak kabul edilebilir (Bauri vd., 2018: 224). Bugün 9835 kripto para biriminin işlem gördüğü piyasanın \%40'ına hâkim olan Bitcoin, pazarın lideri konumundadır. Bitcoin'e olan talep, koronavirüs salgınının başlangıcından bu yana küresel olarak artmış ve bu ilgi 2021 yılının başlarında rekor 
seviyelere ulaşmıştır. Covid-19 salgını nedeni ile küresel çapta finansal krizin yaşandığı 2020 Mart ayı başlarında, Bitcoin'in değeri 4.000 \$'ın altındaydı. 2020 Aralık ayında ise, dünyanın en değerli sanal para birimi olarak, 23.000 \$' in üzerinde işlem görmüştür. Bu baş döndürücü artış, büyük ölçüde Covid-19'un ekonomik etkilerine atfedilebilir. Bu süreçte insanlar çevrimiçi alışveriş yapmak zorunda kaldıkça, fiziksel paradan uzaklaşırken, dijital paranın faydaları daha net hale geldi. 2020 yılında bireysel kullanıcıların yanı sıra kurumsal firmalarda kripto para birimlerine büyük ilgi gösterdi. FED başta olmak üzere, birçok merkez bankası salgın ile mücadele etmek için para basmayı tercih etti. Para basmak ve faiz oranlarını düşürmek gibi dünyadaki merkez bankalarının enflasyonist politikaları, daha fazla kurumsal oyuncuyu kripto paraya yöneltti. Covid-19 sürecinde kripto varlık sektöründeki bu hızlı büyümenin sebebi, kurumsal yatırımcıların paralarını Bitcoin ve diğer kripto varlıklar da dahil olmak üzere alternatif yatırımlara yönlendirmesine bağlanabilir. Covid-19 salgınının pandemi olarak ilan edildiği 2020 Mart ayında değeri çok düşük olan, hatta piyasadan silineceği yönünde yorumlar yapılan Bitcoin'in, piyasa değeri ilerleyen süreçte aşırı derecede artmıştır. Diğer taraftan bir ödeme aracı olarak sınırlı kullanılabilirliği, Bitcoin'in bir yatırım varlığı mı? Altın benzeri bir değer deposu mu? yoksa Bir para birimi mi? olduğu sorusunu akla getirmektedir (Baur, 2018:103). Bu durumda, Bitcoin'in bir yatırım olarak kabulü ve artan talebi göz önüne alındığında, Bitcoin fiyat hareketlerini belirlemek yatırım kararları ve risk yönetimi için önemli hale gelmektedir. Bu noktada çalışmada siyasi, ekonomik ve sosyal gündemde meydana gelebilecek gelişmelerden hızlı bir şekilde etkilenen ve yatırımcıların en çok tercih ettiği emtia listesinin başında yer alan altın ve petrolün, Covid-19 sürecinde, fiyatlarında meydana gelen şokların Bitcoin üzerindeki asimetrik etkisi belirlenmeye çalışılmıştır. Literatürde yer alan çalışmalarda, Bitcoin'in ortaya çıkışından sonraki dönemde altın ve petrol fiyatları ile ilişskisi araştırılmış ancak pandemi sürecindeki etkileri ortaya koyan bir çalışmaya rastlanmamıştır. $\mathrm{Bu}$ noktada çalışmanın literatüre katkı sağlayacağı düşünülmektedir.

\section{Literatür}

Wang vd. (2016), Bitcoin fiyatı ile hisse senedi endeksi, petrol fiyatı ve Bitcoin günlük işlem hacmi arasındaki ilişkiyi 2011:01-2016:04 tarihleri arası aylık verileriyle, eşbütünleşme analizi ve VEC (Vektör Hata Düzeltme) modelini kullanarak analiz etmişlerdir. Analiz sonuçları, dört değişken arasında uzun vadeli denge ve kısa vadeli dinamik bir ilişki olduğunu göstermiştir. Kısa dönem sonuçları, petrol fiyatının ve bitcoin işlem hacminin bitcoin fiyatı üzerinde çok az etkiye sahip olduğunu, hisse senedi fiyat endeksinin ise nispeten daha büyük bir etkiye sahip olduğunu ortaya koymuştur. Uzun vadede ise, hisse senedi fiyat endeksi ve 
petrol fiyatı, bitcoin fiyatı üzerinde olumsuz bir etkiye sahipken, Bitcoin'in fiyatının günlük işlem hacminden olumlu etkilendiği belirlenmiştir.

Dirican ve Canoz (2017) tarafından Bitcoin ile dünyadaki başlıca borsa endeksleri arasındaki eşbütünleşme ilişkisi, 2013:05-2017:11 yılları arası haftalık gözlemler ile analiz edilmiştir. ARDL sınır testi yönteminin kullanıldığı çalışmada Bitcoin'in ABD ve Çin Borsası ile arasında eşbütünleşme ilişkisi görülürken; İngiltere, Japonya ve Türkiye borsaları ile arasında eşbütünleşme ilişkisi görülmemiştir.

Baur vd. (2018), Bitcoin, altın ve ABD doları arasındaki ilişkiyi 19 Temmuz 2010- 22 Mayıs 2015 yılları arası günlük verilerle GARCH modelini kullanarak analiz etmişlerdir. Sonuçlar, Bitcoin'in altın ve ABD doları dahil diğer varlıklara kıyasla belirgin şekilde farklı getiri, oynaklık ve korelasyon özellikleri sergilediğini göstermiştir.

Çütçü ve Kılıç (2018), Bitcoin fiyatları ile dolar kuru arasındaki ilişkiyi 2013:112018:03 dönemleri arası haftalık verilerle yapısal kırılmalı eşbütünleşme testleri ve nedensellik testleri ile incelemişlerdir. Nedensellik testi sonuçlarına göre dolar kurundan Bitcoin fiyatlarına doğru tek yönlü bir ilişki tespit edilmiş ve uzun vadede değişkenler arasında eşbütünleşme ilişkisi olduğu sonucuna ulaşılmıştır.

Bouri vd. (2018), toplam emtia endeksinin ve altın fiyatlarının Bitcoin fiyatı üzerindeki asimetrik etkilerini NARDL yöntemiyle inceledikleri çalışmalarında 17 Temmuz 2010'dan 2 Şubat 2017'ye kadar günlük verileri kullanmışlardır. Sonuçlar, toplam emtia endeksinden ve altın fiyatlarından alınan fiyat bilgilerine dayalı olarak, Bitcoin fiyat hareketlerinin tahmin edilebileceğini göstermiştir.

Güleç vd. (2018), kripto para birimi Bitcoin'in döviz kuru, borsa, faiz oranı ve altın ile olan ilişkisini 2012:03-2018:05 dönemi aylık verileriyle eşbütünleşme ve nedensellik testlerini kullanarak analiz etmişlerdir. Sonuç olarak, Bitcoin ile faiz oranı arasında istatistiksel olarak anlamlı bir ilişki olduğu tespit edilmiştir.

Erdaş ve Çağlar (2018), Bitcoin ile döviz kuru, emtialar ve küresel endeksler arasındaki ilişkileri, asimetrik nedensellik testi ile 2013:11-2018:07 dönemine ait haftalık verilerle incelemişlerdir. Sonuçlar, sadece Bitcoin fiyatından S\&P 500 endeksine doğru tek yönlü bir nedensel ilişki olduğunu göstermiştir. Bitcoin fiyatı ile diğer değişkenler arasında ise nedensellik ilişkisinin varlığı belirlenememiştir.

Deniz ve Teker (2019), altın, brent petrol ve Bitcoin arasındaki ilişkiyi belirlemek için 28.04.2013-23.07.2019 dönemi günlük veriler ile analiz etmişlerdir. Çalışmada, altının ve 
brent petrol fiyatlarının Bitcoin' in günlük fiyatları üzerinde güçlü bir etkisinin olmadığı sonucu elde edilmiştir.

Öztürk (2020), bitcoin, altın ve ham petrol arasındaki ilişkiyi 2017:01-2019:12 tarihleri arası günlük verilerle analiz etmiştir. Çalışma sonuçları, bu üç varlık arasında çeşitlendirmenin kısa ve orta vadede daha zor olmasına rağmen, yatırımcıların uzun vadede çeşitlendirmeden yararlanabileceğini göstermiştir.

Jareno vd. (2020), Bitcoin getirilerinin altın fiyatı getirilerindeki değişikliklere ve ABD hisse senedi piyasası getirileri, faiz oranları, ham petrol fiyatları, Amerikan borsası dalgalanma endeksi (VIX) ve Saint Louis finansal stres endeksi (STLFSI) gibi bazı uluslararası risk faktörlerine duyarlılığını analiz etmişlerdir. 2010-2018 dönemi verilerinin kullanıldığ çalışmada NARDL yöntemi uygulanmıştır. Sonuç olarak Bitcoin ve altın fiyat getirileri arasında pozitif ve istatistiksel olarak anlamlı bir ilişki olduğu belirlenmiştir. Ayrıca VIX ve STLFSI endekslerindeki değişikliklerin Bitcoin getirileri üzerinde olumsuz ve istatistiksel olarak anlamlı etkileri olduğu ortaya konulmuştur.

Thampanya vd. (2020), altın ve kripto paraların Tayland borsası üzerindeki kısa ve uzun vadeli asimetrik etkilerini NARDL modeliyle analiz etmişlerdir. Çalışma sonucunda, altın ve kripto para birimlerinin borsada riskten korunmak için iyi bir araç olmadığı tespit edilmiştir.

Telek ve Şit (2020) tarafından Bitcoin ile altın fiyatları ve dolar endeksi arasındaki ilişki, 2012-2019 yılları arası aylık verilerle, ARDL sınır testi modeli kullanılarak analiz edilmiştir. Sonuç olarak kısa vadede değişkenler arasında eşbütünleşme ilişkisi olmadığı tespit edilirken, uzun vadede eşbütünleşme ilişkisi olduğu belirlenmiştir. Uzun vadede altın fiyatlarındaki \%1'lik bir artışın Bitcoin fiyatlarını \%15 arttıracağı, dolar endeksindeki \%1'lik bir artışın ise Bitcoin fiyatlarını \%0,28 arttıracağı sonucu elde edilmiştir.

Gonzalez vd. (2020), Bitcoin getirileri ile ilk 10 kripto para biriminin getirisi arasındaki ilişkiyi inceledikleri çalışmalarında, Ocak 2015-Mart 2020 dönemleri arası çeşitli verileri (günlük, haftalık ve aylık) kullanmışlardır. Çalışmada, uzun vadede kripto para birimleri arasında anlamlı ve pozitif ilişkiler olduğu belirlenmiştir. Ayrıca, Bitcoin dışındaki kripto paraların getirilerinin, Bitcoin getirilerindeki olumlu ve olumsuz değişikliklere aynı şekilde tepki verdiği ve kısa vadede güçlü bir asimetrik ilişki olduğu sonucuna ulaşılmıştır.

Junior vd. (2020), varlık sınıflarının riskten korunma ve çeşitlendirme potansiyellerini oluşturmak için altın ve sekiz kripto para biriminin ayrıştırılmış getiri serisinin simetrik ve asimetrik bağımlılık yapısını araştırmışlardır. Çalışma sonuçları, kripto para birimlerinin ve altının birbirleri için hem riskten korunma hem de çeşitlendirme aracı olabileceğini 
göstermiştir. Ayrıca hem altının hem de kripto para birimlerinin ham petrol, itibari para birimleri ve diğer emtialar gibi diğer geleneksel varlık sınıfları için korunma ve çeşitlendirme aracı olabileceğini belirtmişlerdir.

Aksoy vd. (2020), Toda-Yamamoto nedensellik analizini kullanarak, 18.01.201824.12.2019 dönemi günlük verileriyle beş kripto para arasındaki ilişkiyi araştırmışlardır. Analiz sonuçları, Ethereum'un diğer 4 kripto paranın fiyatını etkilediği ve diğer 4 kripto paranın Litecoin fiyatını etkilediğini göstermiştir.

Güven ve Bulut (2021), Bitcoin'in altın, petrol, dolar ve euro para birimleri ile arasındaki korelasyon ilişkisini 2012:01-2020:03 dönemleri arası aylık verileriyle inceledikleri çalışmalarında, Bitcoin ile petrol arasında negatif yönde ve zayıf bir ilişki olduğunu; altın, dolar ve euro ile arasında kuvvetli ve anlamlı bir ilişkinin olduğunu belirlemişlerdir.

Demir vd. (2021), NARDL modelini kullanarak Bitcoin'in üç altcoin (Ethereum, Ripple ve Litecoin ) üzerindeki asimetrik etkisini Temmuz 2015 - Mart 2019 dönemi için incelemişlerdir. Sonuç olarak hem kısa vadede hem de uzun vadede Bitcoin'in altcoinler üzerinde asimetrik bir etkisi olduğu görülmüştür.

Ghorbel ve Jeribi (2021), beş kripto para (Bitcoin, Dash, Ethereum, Monero ve Ripple) birimindeki dalgalanmaları, kripto paralar ile Amerikan endeksleri (S \& P500, Nasdaq ve VIX), petrol ve altın arasındaki ilişkileri analiz etmişlerdir. Çalışma sonuçları, kripto para birimleri arasında daha yüksek volatilite olduğu ve kripto para birimleri ile finansal varlıklar arasında daha düşük volatilite olduğunu göstermiştir.

Tablo 1'de literatür özeti sunulmuştur.

Tablo 1: Bitcoin, Altın ve Petrol Fiyatları Arasındaki İlişkiye Ait Literatür Özeti

\begin{tabular}{|l|l|l|l|}
\hline Yazar(lar) & $\begin{array}{l}\text { Veri } \\
\text { Dönemi }\end{array}$ & Değişkenler & Bulgular \\
\hline $\begin{array}{l}\text { Wang vd. } \\
(2016)\end{array}$ & $\begin{array}{l}\text { 2011:01- } \\
2016: 04 \\
\text { aylık veriler }\end{array}$ & $\begin{array}{l}\text { Bitcoin fiyatı ile hisse } \\
\text { senedi endeksi, petrol } \\
\text { fiyatı ve Bitcoin günlük } \\
\text { işlem hacmi }\end{array}$ & $\begin{array}{l}\text { Analiz sonuçları, dört değişken } \\
\text { arasında uzun vadeli denge ve kısa } \\
\text { vadeli dinamik bir ilişki olduğunu } \\
\text { göstermiştir. }\end{array}$ \\
\hline $\begin{array}{l}\text { Dirican ve } \\
\text { Canoz } \\
(2017)\end{array}$ & $\begin{array}{l}2013: 05- \\
2017: 11 \\
\text { haftalık } \\
\text { veriler }\end{array}$ & $\begin{array}{l}\text { Bitcoin fiyatları ile } \\
\text { dünyadaki başlıca borsa } \\
\text { endeksleri }\end{array}$ & $\begin{array}{l}\text { Çalışmada Bitcoin'in ABD ve Çin } \\
\text { Borsası ile arasında eşbütünleşme } \\
\text { ilişkisi görülürken; İngiltere, Japonya } \\
\text { ve Türkiye borsaları ile arasında } \\
\text { eşbütünleşme ilişkisi görülmemiştir. }\end{array}$ \\
\hline $\begin{array}{l}\text { Baur vd. } \\
(2018)\end{array}$ & $\begin{array}{l}19.07 .2010- \\
\text { günlük } \\
\text { veriler }\end{array}$ & $\begin{array}{l}\text { Bitcoin, altın ve ABD } \\
\text { doları }\end{array}$ & $\begin{array}{l}\text { Sonuçlar, Bitcoin'in altın ve ABD } \\
\text { doları dahil diğer varlıklara kıyasla } \\
\text { belirgin şekilde farklı getiri, oynaklik } \\
\text { ve kerelasyon } \\
\text { sergilediğini göstermiştir özellikleri }\end{array}$ \\
\hline
\end{tabular}




\begin{tabular}{|c|c|c|c|}
\hline $\begin{array}{l}\text { Çütçü ve } \\
\text { K1lıç } \\
(2018)\end{array}$ & $\begin{array}{l}\text { 2013:11- } \\
\text { 2018:03 } \\
\text { haftal1k } \\
\text { veriler }\end{array}$ & $\begin{array}{l}\text { Bitcoin fiyatları ile dolar } \\
\text { kuru }\end{array}$ & $\begin{array}{l}\text { Nedensellik testi sonuçlarına göre } \\
\text { dolar kurundan Bitcoin fiyatlarına } \\
\text { doğru tek yönlü bir ilişki tespit } \\
\text { edilmiş ve uzun vadede değişkenler } \\
\text { arasında eşbütünleşme ilişkisi olduğu } \\
\text { sonucuna ulaşılmıştır. }\end{array}$ \\
\hline $\begin{array}{l}\text { Bouri vd. } \\
(2018)\end{array}$ & \begin{tabular}{|l|} 
17.07.2010- \\
2.02 .2017 \\
günlük \\
veriler
\end{tabular} & $\begin{array}{l}\text { Toplam emtia endeksi, } \\
\text { altın fiyatları } \\
\text { ve Bitcoin fiyatı }\end{array}$ & $\begin{array}{l}\text { Sonuçlar, toplam emtia endeksinden } \\
\text { ve altın fiyatlarından alınan fiyat } \\
\text { bilgilerine dayalı olarak, Bitcoin fiyat } \\
\text { hareketlerinin tahmin edilebileceğini } \\
\text { göstermiştir. }\end{array}$ \\
\hline $\begin{array}{l}\text { Güleç vd. } \\
(2018)\end{array}$ & \begin{tabular}{|l|} 
2012:03- \\
2018:05 \\
aylik veriler \\
\end{tabular} & $\begin{array}{l}\text { Bitcoin, döviz kuru, } \\
\text { borsa, faiz oran1 ve altın } \\
\text { fiyatları }\end{array}$ & $\begin{array}{l}\text { Sonuç olarak, Bitcoin ile faiz oranı } \\
\text { arasında istatistiksel olarak anlamlı } \\
\text { bir ilişki olduğu tespit edilmiştir. }\end{array}$ \\
\hline $\begin{array}{l}\text { Erdaş ve } \\
\text { Çağlar } \\
(2018)\end{array}$ & $\begin{array}{l}\text { 2013:11- } \\
\text { 2018:07 } \\
\text { haftalik } \\
\text { veriler }\end{array}$ & $\begin{array}{l}\text { Bitcoin, döviz kuru, } \\
\text { emtialar ve küresel } \\
\text { endeksler }\end{array}$ & $\begin{array}{l}\text { Sonuçlar, sadece Bitcoin fiyatından } \\
\text { S\&P } 500 \text { endeksine doğru tek yönlü } \\
\text { bir nedensel ilişki olduğunu } \\
\text { göstermiştir. Bitcoin fiyatı ile diğer } \\
\text { değişkenler arasında ise nedensellik } \\
\text { ilişkisinin varlığı belirlenememiştir. }\end{array}$ \\
\hline $\begin{array}{l}\text { Deniz ve } \\
\text { Teker } \\
(2019)\end{array}$ & \begin{tabular}{|l|}
$28.04 .2013-$ \\
23.07.2019 \\
günlük \\
veriler \\
\end{tabular} & $\begin{array}{l}\text { Altın, brent petrol ve } \\
\text { Bitcoin }\end{array}$ & $\begin{array}{l}\text { Çalışmada, altının ve brent petrol } \\
\text { fiyatlarının Bitcoin'in günlük } \\
\text { fiyatları üzerinde güçlü bir etkisinin } \\
\text { olmadığı sonucu elde edilmiştir. }\end{array}$ \\
\hline $\begin{array}{l}\text { Öztürk } \\
(2020)\end{array}$ & $\begin{array}{l}\text { 2017:01- } \\
\text { 2019:12 } \\
\text { günlük } \\
\text { veriler }\end{array}$ & $\begin{array}{l}\text { Bitcoin, altın ve ham } \\
\text { petrol }\end{array}$ & $\begin{array}{l}\text { Çalışma sonuçları, üç değişken } \\
\text { arasında çeşitlendirmenin kısa ve orta } \\
\text { vadede daha zor olmasına rağmen, } \\
\text { yatırımcıların uzun vadede } \\
\text { çeşitlendirmeden yararlanabileceğini } \\
\text { göstermiştir. }\end{array}$ \\
\hline $\begin{array}{ll}\text { Jareno } & \text { vd. } \\
(2020) & \end{array}$ & $\begin{array}{l}\text { 2010-2018 } \\
\text { dönemi }\end{array}$ & 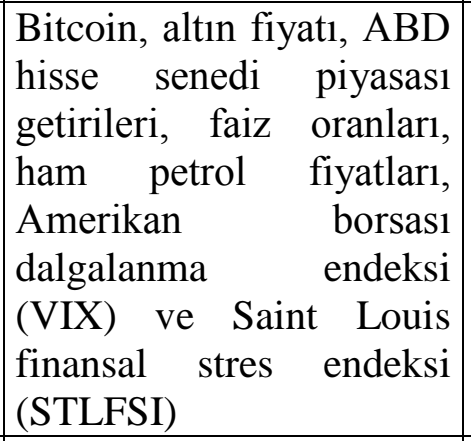 & $\begin{array}{l}\text { Sonuç olarak Bitcoin ve altın fiyat } \\
\text { getirileri arasında pozitif ve } \\
\text { istatistiksel olarak anlamlı bir ilişki } \\
\text { olduğu belirlenmiştir. Ayrıca VIX ve } \\
\text { STLFSI endekslerindeki } \\
\text { değişikliklerin Bitcoin getirileri } \\
\text { üzerinde olumsuz ve istatistiksel } \\
\text { olarak anlamlı etkileri olduğu ortaya } \\
\text { konulmuştur. }\end{array}$ \\
\hline $\begin{array}{l}\text { Thampanya } \\
\text { vd. (2020) }\end{array}$ & $\begin{array}{l}2000-2019 \\
\text { ve } 2013- \\
2019 \\
\text { dönemi }\end{array}$ & $\begin{array}{l}\text { Altın, kripto paralar } \\
\text { veTayland borsası }\end{array}$ & $\begin{array}{l}\text { Çalışma sonucunda, altın ve kripto } \\
\text { para birimlerinin borsada riskten } \\
\text { korunmak için iyi bir araç olmadığ } \\
\text { tespit edilmiştir. }\end{array}$ \\
\hline $\begin{array}{l}\text { Telek ve Şit } \\
(2020)\end{array}$ & $\begin{array}{l}2012-2019 \\
\text { aylik } \\
\text { verilerle }\end{array}$ & $\begin{array}{l}\text { Bitcoin ile altın fiyatları } \\
\text { ve dolar endeksi }\end{array}$ & $\begin{array}{l}\text { Sonuç olarak kisa vadede değişkenler } \\
\text { arasında eşbütünleşme ilişkisi } \\
\text { olmadığ1 tespit edilirken, uzun } \\
\text { vadede eşbütünleşme ilişkisi olduğu } \\
\text { belirlenmiştir. }\end{array}$ \\
\hline
\end{tabular}




\begin{tabular}{|c|c|c|c|}
\hline $\begin{array}{l}\text { Gonzalez } \\
\text { vd. }(2020)\end{array}$ & \begin{tabular}{|l|} 
Ocak 2015- \\
Mart 2020 \\
(günlük, \\
haftalık ve \\
aylık)
\end{tabular} & $\begin{array}{l}\text { Bitcoin getirileri ile ilk } 10 \\
\text { kripto } \\
\text { para biriminin getirisi }\end{array}$ & $\begin{array}{l}\text { Çalışmada, uzun vadede kripto para } \\
\text { birimleri arasında anlamlı ve pozitif } \\
\text { ilişkiler olduğu belirlenmiştir }\end{array}$ \\
\hline $\begin{array}{l}\text { Junior vd. } \\
(2020)\end{array}$ & $\begin{array}{l}\text { 30.04.2013- } \\
18.04 .2019 \\
\text { günlük } \\
\text { veriler }\end{array}$ & $\begin{array}{l}\text { Altin ve sekiz kripto para } \\
\text { (Bitcoin, Dash, Ethereum, } \\
\text { Litecoin, Monero, Nem, } \\
\text { Ripple, Stellar) }\end{array}$ & $\begin{array}{l}\text { Çalışma sonuçları, kripto para } \\
\text { birimlerinin ve altının birbirleri için } \\
\text { hem riskten korunma hem de } \\
\text { çeşitlendirme aracı olabileceğini } \\
\text { göstermiştir. }\end{array}$ \\
\hline $\begin{array}{ll}\text { Aksoy } & \text { vd. } \\
(2020) & \end{array}$ & \begin{tabular}{|l|} 
18.01.2018- \\
24.12.2019 \\
günlük \\
veriler
\end{tabular} & $\begin{array}{l}\text { Beş kripto para (Bitcoin, } \\
\text { Ethereum, Ripple, } \\
\text { Bitcoin cash, Litecoin) }\end{array}$ & $\begin{array}{l}\text { Analiz sonuçları, Ethereum'un diğer } \\
4 \text { kripto paranın fiyatını etkilediği ve } \\
\text { diğer } 4 \text { kripto paranın Litecoin } \\
\text { fiyatını etkilediğini göstermiştir. }\end{array}$ \\
\hline $\begin{array}{l}\text { Güven ve } \\
\text { Bulut } \\
(2021)\end{array}$ & $\begin{array}{l}\text { 2012:01- } \\
\text { 2020:03 } \\
\text { aylik veriler }\end{array} \mid$ & $\begin{array}{l}\text { Bitcoin, altın, petrol, dolar } \\
\text { ve euro }\end{array}$ & $\begin{array}{l}\text { Çalışmada, Bitcoin ile petrol arasında } \\
\text { negatif yönde ve zayıf bir ilişki } \\
\text { olduğunu; altın, dolar ve euro ile } \\
\text { arasında kuvvetli ve anlamlı bir } \\
\text { ilişkinin olduğunu belirlemişlerdir. }\end{array}$ \\
\hline $\begin{array}{l}\text { Demir } \\
(2021)\end{array}$ & \begin{tabular}{|l|} 
Temmuz \\
2015 - Mart \\
2019 \\
dönemi \\
\end{tabular} & $\begin{array}{l}\text { Bitcoin ve altcoinler } \\
\text { (Ethereum, Ripple ve } \\
\text { Litecoin) }\end{array}$ & $\begin{array}{l}\text { Sonuç olarak hem kisa vadede hem } \\
\text { de uzun vadede Bitcoin'in altcoinler } \\
\text { üzerinde asimetrik bir etkisi olduğu } \\
\text { görülmüştür. }\end{array}$ \\
\hline $\begin{array}{l}\text { Ghorbel ve } \\
\text { Jeribi } \\
(2021)\end{array}$ & \begin{tabular}{|l|}
$01.01 .2016-$ \\
01.04 .2020 \\
günlük \\
veriler
\end{tabular} & $\begin{array}{l}\text { Beş kripto para (Bitcoin, } \\
\text { Dash, Ethereum, Monero } \\
\text { ve Ripple), Amerikan } \\
\text { endeksleri (S \& P500, } \\
\text { Nasdaq ve VIX), petrol ve } \\
\text { altın }\end{array}$ & $\begin{array}{l}\text { Çalışma sonuçları, kripto para } \\
\text { birimleri arasında daha yüksek } \\
\text { volatilite olduğu ve kripto para } \\
\text { birimleri ile finansal varliklar } \\
\text { arasında daha düşük volatilite } \\
\text { olduğunu göstermiştir. }\end{array}$ \\
\hline
\end{tabular}

\section{Yöntem}

Çalışmada, Covid-19 sürecinde altın ve petrol fiyatlarında meydana gelen şokların Bitcoin üzerindeki asimetrik etkisini test etmek için NARDL yöntemi uygulanmıştır. Shin vd. (2014) tarafından önerilen NARDL yaklaşımı, geleneksel ARDL modeline göre çeşitli avantajlara sahiptir. Birincisi, asimetrilerin doğrusal olmayan bir şekilde incelenmesine izin verir, dolayısıyla doğrusallık varsayımını ihlal eder. İkinci olarak, NARDL modeli, açıklayıcı değişkenlerin pozitif ve negatif etkilerinin bağımlı değişken üzerindeki kısa ve uzun dönem asimetrik etkilerini inceler (Çıtak vd., 2020:3). Son olarak, modele dahil edilen değişkenlerin durağan ya da aynı dereceden entegre olmasını gerektirmez. Modele eklenen değişkenlerin ikinci farkında durağan olmaması yeterlidir. Bir diğer avantajı ise NARDL yönteminin temelini oluşturan ARDL yönteminin küçük örneklem özelliklerinin geleneksel ekonometrik modellere kıyasla çok daha güçlü olmasıdır (Küçüksoy ve Akkoç, 2020:195). Buna göre değişkenler arasındaki NARDL modeli aşağıdaki eşitlikle ifade edilebilir:

$$
\mathrm{yt}=\lambda \mathrm{Pt}+\beta^{+} x_{t}^{+}+\beta-x_{t}^{-}+\varepsilon_{i}
$$


Burada, $\beta+$ ve $\beta$ - katsayıları uzun dönem parametreleridir ve xt, denklem (2)'deki gibi ayrıştırılmış regresörlerin $\mathrm{k} \times 1$ vektörüdür:

$$
\mathrm{xt}=\mathrm{x} 0+x_{t}^{+}+x_{t}^{-}
$$

Burada, $x t+$ ve $x t-, x t^{\prime}$ de ki pozitif ve negatif değişmelerin kümülatif toplamlarıdır ve aşağıdaki gibi hesaplanmaktadır.

$$
\begin{gathered}
x_{t}^{+}=\Sigma_{j=1}^{t} \Delta x_{j}^{+}=\Sigma_{i=1}^{t} \max (\Delta \mathrm{xj}, 0) \\
x_{t}^{-}=\Sigma_{j=1}^{t} \Delta x_{j}^{-}=\Sigma_{i=1}^{t} \min (\Delta \mathrm{xj}, 0)
\end{gathered}
$$

Denklem (1) ile ilişkilendirilerek, asimetrik hata düzeltme modeli aşağıdaki gibi ifade edilir:

$$
\Delta \mathrm{yt}=\rho \mathrm{yt}-1+\theta+\mathrm{x}_{t-1}^{+}+\theta-\mathrm{x}_{t-1}^{-}+\sum_{J=1}^{p-1} \varphi \mathrm{j} \Delta \mathrm{yt}-\mathrm{j}+\sum_{j=0}^{q}\left(\pi \mathrm{j}+\Delta x_{t-j}^{+}+\pi \mathrm{j}-\Delta x_{t-j}^{-}\right)+\varepsilon_{i}(5)
$$

Burada, $\pi j+$ ve $\pi j-$, xt' deki pozitif ve negatif değişikliklerin kısa vadeli katsayılarıdır. yt, $x_{t}^{+}$ve $x_{t}^{-}$değişkenleri arasında eşbütünleşme ilişkisini test etmek için, $\rho=\theta+=\theta-=0$ sıfır hipotezi Wald testine tabi tutulur. Elde edilen sonuçlar, Pesaran vd. (2001) tarafindan geliştirilen ilgili tablo değerleri ile karşılaştırılır. Böylece değişkenler arasında uzun dönemli ilişki olup olmadığına karar verilir. Wald testi, denklem (5) 'de uzun ve kısa dönem asimetrileri test etmek için kullanılır. Wald testi kullanılarak, uzun vadeli asimetri $\beta^{+}=\beta$ - boş hipotezi ile test edilmektedir. Boş hipotezin reddedilmesi değişkenler arasında asimetrik ilişkinin olduğunu gösterir ve sırasıyla uzun dönem pozitif ve negatif katsayılar $\beta^{+}=-\frac{\theta+}{\rho}$ ve $\beta-=-\frac{\theta-}{\rho}$ şeklinde hesaplanır. Kısa dönem asimetri ise, $\Sigma_{j=0}^{q} \pi \mathrm{j}+=\sum_{j=0}^{q} \pi \mathrm{j}$ - şeklinde oluşturulan boş hipotez ile test edilir ve boş hipotezin reddedilmesiyle değişkenler arası asimetrik ilişkinin varlığı kabul edilir (Aksu ve Başar, 2016:279).

\section{Veri Seti ve Analiz Bulguları}

Çalışmada, tüm dünyayı etkisi altına alan Covid-19 salgınının yaşandığı süreçte, altın ve petrol fiyatlarında meydana gelen pozitif ve negatif şokların Bitcoin fiyatları üzerindeki kısa ve uzun vadeli asimetrik etkilerini belirlemek amaçlanmıştır. Bu amaçla 26.01.202028.02.2021 tarihleri arası haftalık veriler NARDL yöntemiyle analiz edilmiştir. Çalışmada 26.01.2021 tarihinin başlangıç olarak kabul edilmesinin nedeni, Dünya Sağlık Örgütü (World Health Organization- WHO) veri tabanında dünya genelindeki Covid-19 vakalarının rapor edildiği ilk hafta olmasıdır. Tablo 2'de ekonometrik analiz için kullanılan verilerin özeti sunulmuştur.

Tablo 2: Çalışmada Kullanılan Verilere İlişkin Bilgiler

\begin{tabular}{|l|l|l|}
\hline Sembol & Değişken & Kaynak \\
\hline
\end{tabular}




\begin{tabular}{|c|c|c|}
\hline BTC & Bitcoin Fiyatları & \\
\hline ALT & Altın ons fiyatı & investing.com \\
\hline $\mathrm{BPF}$ & Brent Petrol Fiyatları & \\
\hline
\end{tabular}

Tablo 3 değişkenlere ait birim kök testi sonuçlarını göstermektedir. Tablo 3'deki birim kök testi sonuçlarına göre, LNBPF sabit ve trend modelde düzeyde durağan iken, LNBTC ve LNALT değişkenleri ilk farkta durağandır. Dolayısıyla, LNBTC ve LNALT değişskenlerinin I (1)’de, LNBPF değişkeninin ise I (0)'da durağan olduğunu söyleyebiliriz.

Tablo 3: ADF ve PP Birim Kök Testi Sonuçları

\begin{tabular}{|c|c|c|c|c|}
\hline & \multicolumn{2}{|c|}{$\mathrm{ADF}$} & \multicolumn{2}{|c|}{ PP } \\
\hline \multicolumn{5}{|c|}{ Düzey } \\
\hline $\begin{array}{c}\text { Değişkenler } \\
\text { LNBTC } \\
\text { LNALT } \\
\text { LNBPF } \\
\end{array}$ & $\begin{array}{c}\text { Sabit } \\
\text { t-Stat } \\
0.655278 \\
-2.084080 \\
-2.085567 \\
\end{array}$ & $\begin{array}{c}\text { Sabit ve Trend } \\
\text { t-Stat } \\
-1.513161 \\
-0.688612 \\
-5.278739 * * * \\
\end{array}$ & $\begin{array}{c}\text { Sabit } \\
\text { t-Stat } \\
0.815857 \\
-1.911556 \\
-1.650849 \\
\end{array}$ & $\begin{array}{c}\text { Sabit ve Trend } \\
\text { t-Stat } \\
-1.414479 \\
-1.343942 \\
-2.611391 \\
\end{array}$ \\
\hline \multicolumn{5}{|c|}{ Birinci Fark } \\
\hline $\begin{array}{l}\text { LNBTC } \\
\text { LNALT } \\
\text { LNBPF }\end{array}$ & $\begin{array}{l}-7.332409 * * * \\
-10.07268 * * * \\
-5.916547 * * *\end{array}$ & $\begin{array}{l}-7.795325 * * * \\
-10.33266 * * * \\
-6.086186 * * *\end{array}$ & $\begin{array}{l}-7.332417 * * * \\
-10.44739 * * * \\
-5.826833 * * *\end{array}$ & $\begin{array}{l}-7.923296 * * * \\
-12.14061 * * * \\
-5.973016 * * *\end{array}$ \\
\hline $\begin{array}{c}\text { Kritik Değerler } \\
1 \% \\
5 \% \\
10 \%\end{array}$ & $\begin{array}{c}\text { Sabit } \\
-3.550396 \\
-2.913549 \\
-2.594521\end{array}$ & $\begin{array}{c}\text { Sabit ve Trend } \\
-4.130526 \\
-3.492149 \\
-3.174802\end{array}$ & & \\
\hline
\end{tabular}
***,**,* sırasıyla \%1, \%5 ve \%10 önem düzeyinde durağanlığı ifade etmektedir.

Birim kök testi sonuçlarına göre, değişkenler I (2) ‘de durağan olmadığı için, çalışmada NARDL modeli uygulanabilir. Buna göre, değişkenler arasındaki asimetrik NARDL modeli sonuçları Tablo 4'de yer almaktadır. 
Tablo 4. NARDL Tahmin Sonuçları

\begin{tabular}{|c|c|c|c|}
\hline \multicolumn{4}{|l|}{ Bağımlı Değisşken: $\Delta \operatorname{lnBTC}$} \\
\hline Değişkenler & Katsay 1 & t-İstatistik & Olasilık \\
\hline $\mathrm{C}$ & 3.094539 & 2.701667 & 0.0106 \\
\hline LNBTC(-1)* & $-0.342216^{* * *}$ & -2.929681 & 0.0059 \\
\hline LNALT_POS(-1) & 0.324884 & 0.795812 & 0.4315 \\
\hline LNALT_NEG(-1) & $-3.074965^{* * *}$ & -3.328706 & 0.0021 \\
\hline LNBPF_POS(-1) & -0.253983 & -1.304374 & 0.2006 \\
\hline LNBPF_NEG(-1) & $0.356966^{*}$ & 1.732984 & 0.0919 \\
\hline$\Delta$ LNBTC(-1) & -0.187034 & -1.244162 & 0.1089 \\
\hline$\triangle \mathrm{LNBTC}(-2)$ & -0.217378 & -1.543897 & 0.0730 \\
\hline$\triangle$ LNALT_POS & $2.266711 * * *$ & 2.333021 & 0.0057 \\
\hline$\triangle \mathrm{LNALT}$ _NEG & 1.113766 & 1.203564 & 0.1250 \\
\hline$\Delta$ LNALT_NEG(-1) & $2.818074 * * *$ & 2.642319 & 0.0035 \\
\hline$\triangle$ LNALT_NEG(-2) & $4.431049 * * *$ & 3.885385 & 0.0000 \\
\hline$\Delta$ LNALT_NEG(-3) & $4.352415^{* * *}$ & 3.759771 & 0.0000 \\
\hline$\triangle \mathrm{LNALT}$ _NEG(-4) & $2.446833^{* * *}$ & 2.281685 & 0.0036 \\
\hline$\triangle \mathrm{LNBPF}$ _POS & $1.370280^{* * *}$ & 3.363725 & 0.0000 \\
\hline$\triangle \mathrm{LNBPF}$ NEG & -0.227864 & -0.561304 & 0.3529 \\
\hline$\triangle$ LNBPF_NEG(-1) & $0.586079 * *$ & 1.908448 & 0.0209 \\
\hline ECM & -0.342216 & -6.697137 & 0.0000 \\
\hline \multicolumn{4}{|l|}{ Uzun Dönem Asimetrik Katsayılar } \\
\hline & Katsayı & $\mathrm{t}$-İstatistik & Olasılik \\
\hline$L_{A L T}^{+}$ & 0.949352 & 0.725216 & 0.4731 \\
\hline$L_{A L T}^{-}$ & $-8.985448 * * *$ & -5.205443 & 0.0000 \\
\hline$L_{B P F}^{+}$ & -0.742172 & -1.111455 & 0.2739 \\
\hline \multirow[t]{2}{*}{$L_{B P F}^{-}$} & $1.043101 * * *$ & 2.757933 & 0.0092 \\
\hline & F-İstatistiği & Olasilik & Sonuç \\
\hline Wald $_{\text {LR, ALT }}$ & $25,7474 * * *$ & 0,0000 & Asimetri \\
\hline Wald $_{\mathrm{LR}, \mathrm{BPF}}$ & $5,2864 * *$ & 0,0264 & Asimetri \\
\hline Wald $_{\mathrm{SR}, \mathrm{ALT}}$ & $7.8269 * * *$ & 0.0077 & Asimetri \\
\hline \multirow[t]{2}{*}{ Wald $_{\mathrm{SR}, \mathrm{BPF}}$} & $14.6063 * * *$ & 0.0004 & Asimetri \\
\hline & \multicolumn{3}{|c|}{ Kritik Değerler I(1) } \\
\hline F_istatistik & $\% 1$ & $\% 5$ & $\% 10$ \\
\hline 6,5409 & 4,947 & 3,813 & 3,280 \\
\hline \multicolumn{4}{|l|}{ Diagnostik testler ve Model İstatistikleri } \\
\hline Breusch-Godfrey LM testi & $0,6378(0,5348)$ & $\mathrm{R} 2$ & 0,9864 \\
\hline Breusch-Pagan-Godfrey Değişen Varyans testi & $1,1196(0,3756)$ & Düzeltilmiş R2 & 0,9803 \\
\hline Jarquera-Bera Testi & $5,9321(0,5151)$ & F_istatistiği & $159.822(0,000)$ \\
\hline Ramsey Reset Testi & $1,1488(0,2587)$ & & \\
\hline CUSUM ve CUSUMQ & İstikrarlı & & \\
\hline
\end{tabular}


Notlar: ***, **, * sirasıyla $\% 1, \% 5$ ve $\% 10$ önem düzeyinde anlamlılığı göstermektedir. Tanısal testlere ait olasılık değerleri parantez içerisinde verilmiştir.

Tablo 4'teki eşbütünleşme testi sonuçlarına göre, hesaplanan F istatistik değeri $(6,5409)$ \% 1 önem düzeyindeki I (1) kritik değerinden daha büyüktür. Bu durumda, Bitcoin ile altın ve petrol fiyatları arasında eşbütünleşme olmadığı şeklinde tanımlanan boş hipotez reddedilir ve eşbütünleşme ilişkisinin varlığını kabul eden alternatif hipotez kabul edilir. Diğer bir deyişle, Wald testi sonuçlarıyla birlikte sınır testi de dikkate alındığında, değişkenler arasında uzun vadeli asimetrik bir eşbütünleşme ilişkisi olduğu sonucuna ulaşılmaktadır. Ayrıca, (WLR) ve (WSR) sırasıyla uzun ve kısa dönem asimetriler için, Wald testi sonuçlarını göstermektedir. Wald testi sonuçları hem uzun (WLR) hem kısa vadede altın ve petrol fiyatlarındaki değişikliklerin Bitcoin fiyatlarını asimetrik olarak etkilediğini göstermektedir. NARDL modelinin uzun dönem katsayılarına bakıldığında, altın $\left(L_{A L T}^{+}\right.$ katsayısı pozitif ve anlamsız) ve petrol $\left(L_{B P F}^{+}\right.$katsayısı negatif ve anlamsız) fiyatlarındaki pozitif değişmeleri gösteren katsayıların istatistiki olarak anlamsız olduğu görülmektedir. Uzun dönem altın fiyatlarındaki negatif değişimi gösteren $L_{A L T}^{-}$katsayısının ise negatif ve \%1 önem düzeyinde istatistiki olarak anlamlı olduğu görülmektedir. Buna göre, altın fiyatlarında meydana gelen \%1'lik bir azalmanın, Bitcoin fiyatlarında yaklaşık \%9'luk bir artışa neden olduğu söylenebilir. $L_{B P F}^{-}$katsayısı ise petrol fiyatlarındaki negatif değişimi göstermektedir ve sonuçlarına bakıldığında pozitif ve anlamlıdır. Bu durumda petrol fiyatlarındaki düşüşlerin, Bitcoin fiyatlarını olumsuz etkilediği görülmektedir. Yani petrol fiyatlarındaki \%1'lik bir azalma, Bitcoin fiyatlarını \%1.04 azaltmaktadır.

Kısa dönem sonuçları incelendiğinde, altın fiyatlarında meydana gelen pozitif ve negatif şoklara ait katsayılar, pozitif ve anlamlıdır. Bu durumda altın fiyatlarında kısa dönemde meydana gelen pozitif şokların Bitcoin fiyatlarında artışa, negatif şokların ise Bitcoin fiyatlarında düşüşe neden olduğu söylenebilir. Kısa dönemde petrol fiyatlarındaki pozitif ve negatif şokların katsayılarına bakıldığında pozitif ve anlamlı olduğu görülmektedir. Kısa vadede petrol fiyatındaki pozitif şoklar, Bitcoin fiyatlarını olumlu etkilemekte, negatif şoklar ise Bitcoin fiyatlarını olumsuz etkilemektedir.

Tablo 4'deki tanısal test sonuçlarına göre, NARDL modelinde otokorelasyon (BreuschGodfrey LM testi $=0.6378)$ ve değişen varyans (Breusch-Pagan-Godfrey $=1.1196)$ sorunu olmadığı görülmektedir. Ayrıca normallik testinin değeri (Jarquera-Bera = 5.9321) verilerin normal bir şekilde dağıldığını doğrulamaktadır. Ramsey testinin değeri (1.1488) model kurma hatasının olmadığını göstermektedir. Son olarak, kurulan NARDL modelinde CUSUM ve CUSUMQ (yapısal kırılma testleri) testleri yapılmış ve sonuçlar Şekil 1'de sunulmuştur. Sonuçlara göre, modelin istikrarlı olduğu görülmektedir. 


\section{Şekil 1. CUSUM ve CUSUMQ Grafikleri}

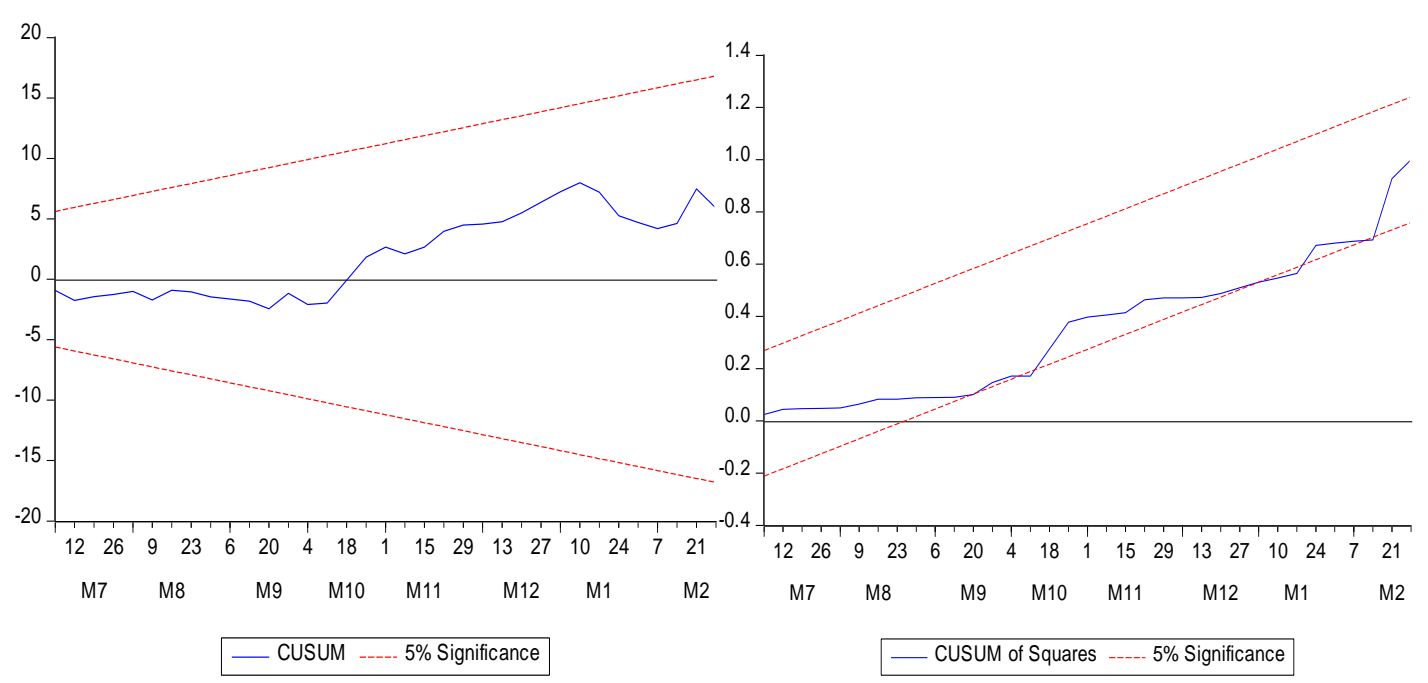

Sonuç

Koronavirüsün ortaya çıkmasıyla birlikte dünya finans piyasaları, kripto varlıklar dahil, yıllar içerisindeki en keskin düşüşlerini yaşadı. Pandeminin getirdiği belirsizliğin yarattığı panik, ekonomik kriz başlamadan önce bir likidite krizine yol açtı. Yatırımcılar, finansal durumlarını korumak için varlıklarını nakde çevirdiler. Kripto para piyasası da bu durumdan etkilendi ve bitcoin ve altcoin fiyatları düştü. Diğer taraftan pandemi süreci, geleneksel finansal araçların zayıflı̆̆ını ortaya çıkardı. Bitcoin'in hızlı toparlanması, kripto para piyasasının dayanıklılığının bir göstergesi oldu. Kripto para piyasası ve özellikle Bitcoin, tüm küresel piyasaların yaşadığı karmaşaya karşı dirençli olduğunu kanıtladı. 2020 yılı mart ayındaki en düşük noktasından istikrarlı bir şekildeki yükseliş trendi, küresel ölçekte Bitcoin'e ve genel olarak kripto para birimlerine olan ilgiyi arttırdı. COVID-19 krizi başlangıcında kripto para birimlerinin ortadan kalkacağı telaffuz edilirken, bireysel yatırımcıların yanı sıra kurumsal yatırımcıların da ilgi göstermesiyle, kripto paralar küresel ekonominin bir parçası olma yolunda hızla ilerledi. Grayscale, Paypal ve Tesla gibi popüler kurumlar yatırımlarını yavaş yavaş kripto paralara çevirmeye başladılar. Özellikle ABD firması Tesla, 1.5 milyar dolarlık Bitcoin satın aldığını ve ek olarak, ürünleri için ödeme olarak Bitcoin'i kabul etmeye başlamayı planladığını duyurdu.

Kripto para piyasasında yaşanan bu olumlu gelişmeler, yatırımcıların portföylerinin çeşitlendirmede bu piyasaya yönlenmesine neden oldu. Çalışmada, pandemi sürecinde en düşük fiyat noktasından hızlı bir artış trendi gösteren, altın ve petrole karşı alternatif yatırım aracı olan Bitcoin'in, altın ve petrol fiyatlarında meydana gelen şoklardan etkilenip etkilenmediği 
belirlenmeye çalış1lmıştır. Çalışmada 26 Ocak 2020-28 Şubat 2021 dönemi arası haftalık veriler kullanılmış ve NARDL yöntemiyle analiz edilmiştir. Analiz sonucunda uzun vadede altın fiyatlarındaki pozitif şokların Bitcoin fiyatları üzerinde istatistiki olarak anlamlı bir etkisi görülmezken, altın fiyatlarındaki negatif şokların Bitcoin fiyatlarını olumlu etkilediği görülmüştür. Altın fiyatlarında meydana gelen \%1'lik bir azalmanın, Bitcoin fiyatlarında yaklaşık \%9'luk bir artışa neden olduğu belirlenmiştir. Yani altın fiyatlarındaki düşüşlerin yatırımcıların Bitcoin'e yönelmesine neden olduğu söylenebilir. Petrol fiyatlarında uzun vadede meydana gelen pozitif şokların Bitcoin fiyatları üzerinde istatistiki olarak anlamlı bir etkisi yokken, negatif şoklar Bitcoin fiyatlarını olumsuz etkilemektedir. Petrol fiyatlarında meydana gelen \%1'lik bir azalma, Bitcoin fiyatlarını \%1.04 azaltmaktadır. Kısa vadede ise hem altın hem de petrol fiyatlarında meydana gelen pozitif şokların Bitcoin fiyatlarında artışa, negatif şokların ise azalışa neden olduğu belirlenmiştir. Sonuçlar, portföylerini çeşitlendirmeyi düşünen yatırımcılar açısından önemlidir. Güvenli bir liman olma özelliği ile bilinen altının negatif şoklarının Bitcoin'in değerinde yarattığı olumlu etkinin, sanal altın olarak ifade edilen Bitcoin'i daha çekici hale getirdiği söylenebilir. Ayrıca, pandeminin yarattığı krizin merkez bankalarının veya siyasi aktörlerin piyasaya müdahale etmesine neden olacağından korkan yatırımcıların, yatırımlarını merkezi olmayan kripto para birimlerine yönlendirmeyi tercih ettiği görülmektedir. Başka bir deyişle, kripto para birimlerinin merkezi bir otorite tarafindan yönetilmemesi, yatırımcıların bazı politik risklerden korunmalarını sağlayarak, daha cazip hale gelmelerini sağlamaktadır. Kısaca Bitcoin'in küresel yatırımcılar için finansal çeşitlendirmede ideal olabileceği ve yeni bir sanal altın olarak piyasalardaki yerini alabileceği söylenebilir. Pandemi sürecince, insanların sanal dünyaya hızlıca giriş yapmaları ve geleceğin dünyasının bu çerçevede şekilleneceği göz önünde bulundurulursa, politika yapıcıların hızlı bir şekilde kripto piyasasının tüm dünyada kabul görmesini sağlayacak yasal düzenlemeleri ortaya koyması gerekmektedir.

Çalışma emtia piyasalarında en fazla yatırım yapılan altın ve petrolün Covid-19 sürecinde, Bitcoin üzerindeki asimetrik etkisine odaklanmıştır. Kripto para birimleri yıllarca hisse senetleri, tahviller ve diğer parasal varlıklara karşı koruma ve güvenli liman olarak kullanılan altına benzetilmiş ve hatta sanal altın olarak ifade edilmiştir. Bu noktada çalışma Bitcoin'in altın ve petrol dışındaki diğer varlıklarla ilişkisine odaklanılarak genişletilebilir. 


\section{Kaynakça}

Aksoy, E., Teker, T., Mazak, M. ve Kocabıyık, T. (2020). Kripto Paralar ve Fiyat İlişkileri Üzerine Bir Analiz: Toda-Yamamoto Nedensellik Analizi İle Bir İnceleme, Süleyman Demirel Üniversitesi Sosyal Bilimler Enstitüsü Dergisi, Say1:37, 110-129.

Aksu, H. ve Başar, S. (2016). Türkiye Ekonomisinde Hasılanın İşsizlik Üzerindeki Dinamik Etkileri, Atatürk Üniversitesi Sosyal Bilimler Enstitüsü Dergisi, 20 (1), 275-286.

Al-Naif, K. L. (2020). The Relationship Between Crypto Currencies and Official Arabian Currencies Exchange Rate, Academy of Accounting and Financial Studies Journal, Volume 24, Issue 2, 1-10.

Baur, D. G., Dimpfl, T. and Kuck, K. (2018). Bitcoin, gold and the US dollar - A replication and extension, Finance Research Letters, Cilt 25, 103-110.

Bouri, E., Gupta, R., Lahiani, A. and Shahbaz, M. (2018). Testing for asymmetric nonlinear short- and long-run relationships between bitcoin, aggregate commodity and gold prices, Resources Policy, (57), 224-235.

Corelli, A. (2018). Cryptocurrencies and Exchange Rates: A Relationship and Causality Analysis, Risks, 6 (4), 1-11.

Çıtak, F., Uslu, H., Batmaz, O. ve Hoş, S. (2020). Do renewable energy and natural gas consumption mitigate $\mathrm{CO} 2$ emissions in the USA? New insights from NARDL approach, Environmental Science and Pollution Research, 1-12

Çütçü, İ. ve Kılıç, Y. (2018). Bitcoin Fiyatları İle Dolar Kuru Arasındaki İlişki: Yapısal Kırılmalı Zaman Serisi Analizi, Yönetim ve Ekonomi Araştırmaları Dergisi, Cilt: 16 Sayı: 4, 349366.

Demir, E., Simonyan, S., Garcia-Gomez, C. D. and Lau, C. K. M. (2021). The asymmetric effect of bitcoin on altcoins: evidence from the nonlinear autoregressive distributed lag (NARDL) model, Finance Research Letters, (40), 1-6.

Deniz, E. A. ve Teker, D. (2019). Determinants of Bitcoin prices. PressAcademia Procedia (PAP), V.10, 17-21.

Dirican, C. ve Canoz, İ. (2017). The cointegration relationship between Bitcoin prices and major world stock indices: an analysis with ARDL model approach. Journal of Economics, Finance and Accounting (JEFA), V.4, Iss.4, 377-392.

Erdaş, M. L. ve Çağlar, A. E. (2018). Analysis of the relationships between Bitcoin and exchange rate, commodities and global indexes by asymmetric causality test, Eastern Journal of European Studies, Volume 9, Issue 2, 27-45.

Ghorbel, A. ve Jeribi, A. (2021). Investigating the relationship between volatilities of cryptocurrencies and other financial assets, Decisions in Economics and Finance, https://doi.org/10.1007/s10203-020-00312-9

Gonzalez, M. O., Jareno, F. and Skinner, F. S. (2020). Nonlinear Autoregressive Distributed Lag Approach: An Application on the Connectedness between Bitcoin Returns and the Other Ten Most Relevant Cryptocurrency Returns, Mathematics, 8, 810, 2-22.

Güleç, Ö. F., Çevik, E. ve Bahadır, N. (2018). Bitcoin ile Finansal Göstergeler Arasındaki İlişkinin İncelenmesi, Kırklareli Üniversitesi İktisadi ve İdari Bilimler Fakültesi Dergisi, Cilt: 7, Say1: 2 (Özel Say1: Finansal Raporlamada Güncel Yaklaşımlar), 18-37.

Güven, Ö. ve Bulut, Ş. (2021). Güncel Haliyle Bitcoin ve Piyasadaki Değeri Üzerine Bir İnceleme, Troyacademy, 6 (1), 80-89. 
Jareno, F., Gonzalez, M. O., Tolentino, M. and Sierra, K. (2020). Bitcoin and gold price returns: A quantile regression and NARDL analysis, Resources Policy (67), 1-14.

Ji, Q., Bouri, E., Gupta, R. and Roubaud, D. (2018). Network causality structures among Bitcoin and other financial assets: A directed acyclic graph approach, The Quarterly Review of Economics and Finance, Vol 70, 203-213.

Junior, P. O., Adam, A. M., Tweneboah, G. and McMillan, D. (2020). Connectedness of cryptocurrencies and gold returns: Evidence from frequency-dependent quantile regressions, Cogent Economics \& Finance, 8(1), 1-19.

Küçüksoy, N. ve Akkoç, U. (2020). Türkiye ile Çin İkili Ticaretinde J Eğrisi: NARDL Yaklaşımı, Ekonomi, Politika \& Finans Araştırmaları Dergisi, 5(2): 190-209.

Öztürk, S. S. (2020). Dynamic Connectedness between Bitcoin, Gold, and Crude Oil Volatilities and Returns, Journal Risk and Financial Management, 13, 275, 1-14.

Pesaran, M.H.; Shin, Y. and Smith, R. J. (2001). Bounds Testing Approaches To The Analysis of Level Relationships, Journal of Applied Econometrics, Vol 16, Issue 3, 289-326.

Shin, Y.; Yu, B. and Greenwood-Nimmo, M., (2014). Modelling asymmetric cointegration and dynamic multipliers in a nonlinear ARDL framework, Sickles, R.C. and Horrace, W.C.(Ed.), Festschrift in Honor of Peter Schmidt, Econometric Methods and Applications, Springer, New York, NY, 281-314

Telek, C. ve Şit, A. (2020). Kripto paraların altın ve dövizle ilişkisi: Bitcoin örneği, Turkish Studies - Economy, 15(2), 913-924.

Thampanya, N., Nasir, M. A. and Huynh, T. L. (2020). Asymmetric correlation and hedging effectiveness of gold \& cryptocurrencies: From pre-industrial to the 4th industrial revolution, Technological Forecasting and Social Change, Volume 159, 1-13.

Wang, J., Xue, Y. and Liu, M. (2016). An Analysis of Bitcoin Price Based on VEC Model, International Conference on Economics and Management Innovations (ICEMI 2016), 146-152.

www. investing.com 